\title{
Mean Platelet Volume as an Inflammatory Marker in Patients with Chronic Periodontitis - A Pilot Study
}

\author{
G. Jagadish Reddy, M. Ramya Chandra, A. Abhinav Gupta, Ravikiran Reddy Vundela, \\ Suryakanth Malgikar, P. Raja Babu \\ Department of Periodontics, Kamineni Institute of Dental Sciences, Sreepuram, Narketpally, Telangana State, India
}

Email for correspondence: drjagadishreddy@gmail.com

\begin{abstract}
Background: Periodontitis is a widespread infectious disease of the periodontium that leads to gingival inflammation and bleeding. It has become the leading cause of tooth loss in adults. Mean platelet volume (MPV), an important index of platelet activity, reflects platelet production rate and stimulation. MPV has been considered an inflammatory marker in many chronic diseases and might reflect disease activity of periodontitis. It was also known that elevated MPV is associated with cardiovascular diseases. Aims and Objectives: The aim of the present study was to investigate the relationship between MPV and chronic periodontitis and short-term effects of active periodontal treatment (APT) on MPV level. Materials and Methods: A total of 13 subjects with chronic generalized periodontitis were selected from OPD, Department of Periodontics, Kamineni Institute of Dental Sciences. All subjects received periodontal and hematological examinations at baseline and 1 week. APT was administered in all the subjects. Results: Decrease of MPV was related to the severe periodontal inflammation and the value inversed shift after active APT. Conclusion: MPV can be used as a diagnostic marker in diagnosing patients with periodontitis and also can be used as a non-pharmacological intervention in improving the platelet activity.
\end{abstract}

Key words: Inflammation markers, mean platelet volume, periodontitis

\section{INTRODUCTION}

Periodontitis is a chronic inflammatory and infectious disease affecting the periodontium, which is mainly caused by the periodontal pathogens and the subsequent reaction of the host to these pathogens. Although the traditionally used clinical diagnostic methods such as bleeding on probing, probing pocket depth, and radiographs help us in reaching a conclusion of existence of the disease, they have certain limitations such as follows:

\begin{tabular}{|l|l}
\hline Quick Response Code & Article Info: \\
\hline doi: 10.5866/2018.10.10155 \\
\hline $\begin{array}{l}\text { Received: } 20-09-2018 \\
\text { Revised: } 28-10-2018 \\
\text { Accepted: } 24-11-2018 \\
\text { Available Online: } 05-01-2019 \text { (www. } \\
\text { nacd.in)@ NAD, } 2019 \text { - All rights } \\
\text { reserved }\end{array}$ \\
\hline
\end{tabular}

1. Inability to assess the active stage of disease.

2. Relation between periodontal inflammation and systemic inflammation cannot be established.

3. Susceptibility of healthy subjects to disease.

4. Precise response to therapy, i.e., reduction in inflammation.

Studies have shown association between periodontitis and many systemic diseases. This plausibility was based on the thought that the periodontal pathogens gain access to the bloodstream. ${ }^{[1]}$ Transient bacteremias in case of periodontitis patients lead to chronic increased production of proinflammatory mediators. ${ }^{[2,3]}$ Systemic inflammation markers help us in knowing the periodontal as well as systemic inflammation, thus linking the oral health to general health status. This could be explained through increased levels of white blood cells, C-reactive protein, and platelet activation. ${ }^{[4-7]}$

Mean platelet volume (MPV) measures the activated platelets and is known as a marker in 
many chronic inflammatory diseases. ${ }^{[8]}$ Hence, the present study was aimed to investigate the MPV value and its relation with periodontitis and change in value of MPV after non-surgical periodontal therapy.

\section{MATERIALS AND METHODS}

\section{Inclusion Criteria}

A total of 13 subjects were recruited from the Department of Periodontics, Kamineni Institute of Dental Sciences, with a diagnosis of chronic generalized periodontitis.

Case definition of periodontitis:

1. Clinical attachment loss greater than or equal to $30 \%$ of the teeth.

2. Periodontal pocket depth of greater than $4 \mathrm{~mm}$ on greater than or equal to $30 \%$ of the teeth.

The patients were categorized as a periodontitis patient if he/she satisfies with one or both the criteria.

\section{Exclusion Criteria}

Following patients were excluded from the study:

1. Former or current smoker.

2. Patients with systemic illnesses.

3. History of periodontal therapy within the past 6 months.

4. History of antibiotic therapy within the past 6 months.

5. Pregnant or lactating women.

\section{Baseline examination and treatment}

Clinical examinations were done to note the sites which bleed on probing, sites with clinical attachment loss, and probing pocket depth. Radiographic examination was done to determine the level of bone loss. Blood examination was performed to rule out the conditions such as diabetes mellitus.

About $2 \mathrm{ml}$ of blood was collected from patients with diagnosis of chronic generalized periodontitis, satisfying the inclusion criteria. Blood was taken by venipuncture and transferred into purple topped anticoagulant tube containing ethylenediaminetetraacetic acid. Blood samples were sent to Kamineni Institute of Medical Sciences for the purpose of complete hemogram within $1 \mathrm{~h}$ of sample collection. A technician who was blinded about the case status performed hemogram. The blood samples were analyzed using Bc 5130 Auto Hematology Analyzer [Figure 1]. Patient received complete scaling in a single visit.

\section{Follow-up Examination}

After 1 week, $2 \mathrm{ml}$ of blood was collected for hemogram analysis and scaling was performed if required.

\section{Statistical Analysis}

The results obtained were tabulated and graphs were plotted, and the data were statistically analyzed using NCSS software (Version 12, Kaysville, USA) using Pearson's correlation coefficient and the results obtained were statistically significant.

\section{RESULTS}

The results of the present study showed high MPV values after active periodontal therapy when compared mean values at baseline [Table 1 and Graph 1]. The post-therapy increase in MPV was related to the decrease in periodontal inflammation.

\section{DISCUSSION}

Platelets, which are the unique mammalian blood cells, participate in breadth of cellular interactions. Platelets get accumulated at the sites of injury, bacterial invasion, and inflammatory exudates and get locally activated..$^{[9-11]}$ After their

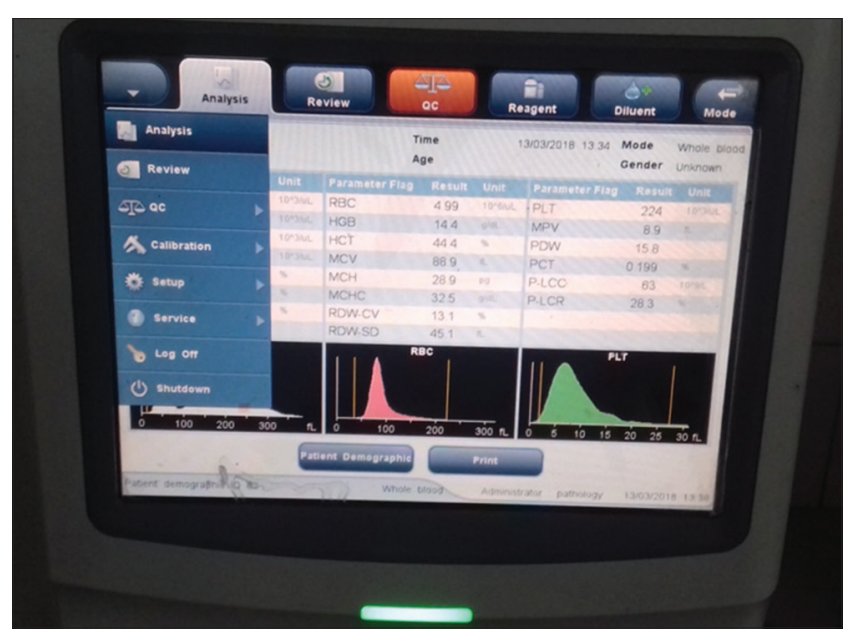

Figure 1: Bc 5130 Auto Hematology Analyzer used for hemogram analysis mean platelet volume

Table 1: Mean MPV values after active periodontal therapy have increased when compared to mean values at baseline which is statistically significant

\begin{tabular}{lccccc}
$\boldsymbol{n}$ & $\begin{array}{c}\text { Pearson } \\
\text { correlation }\end{array}$ & df & t-value & P-value & $\begin{array}{c}\text { Reject H0 } \\
\text { at } \boldsymbol{\alpha = 0 . 0 5 ?}\end{array}$ \\
\hline 13 & 0.7647 & 11 & 3.9359 & 0.0023 & Yes \\
\hline$* P<0.05$ is considered statistically significant, MPV: Mean platelet \\
volume
\end{tabular}




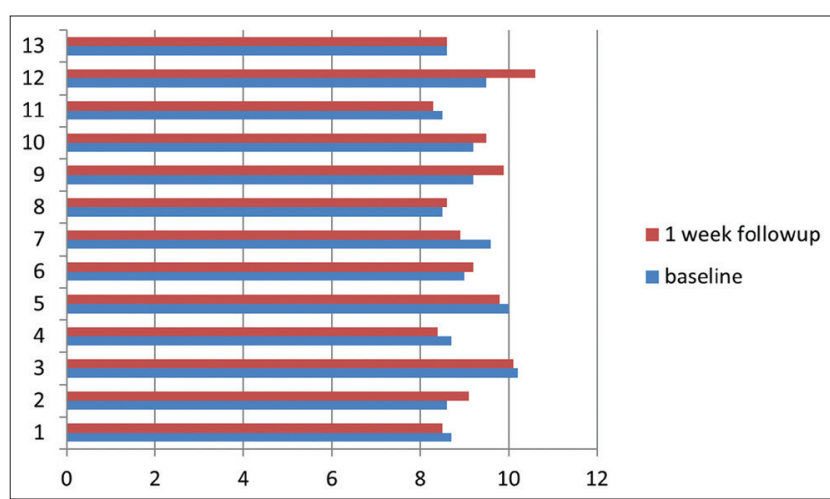

Graph 1: Comparison of mean platelet volume values (in $\mathrm{fL}$ ) at baseline and 1 week

activation, they release products which are either synthesized or secreted which constitutes "platelet secretome." Platelet secretome includes proteins and polysaccharides that are stored in processed or precursor forms and can be released rapidly ${ }^{[12-15]}$ whereas, others are products that are triggered when platelets themselves receive activating signals. ${ }^{[16]}$

Activated platelets secrete pleiotropic inflammatory and immune modulators, inflammatory and immunomodulatory lipids, growth factors, chemokines, antimicrobial peptides, and cytokines. ${ }^{[9-11]}$ Platelets have crucial role in the early events of immune continuum, angiogenesis regulation, and spatially localized information transfer through signaling molecules. ${ }^{[14,17,18]}$

Activated platelets are said to produce thromboxane A2, which forms a therapeutic target in cardiovascular diseases (CVDs). ${ }^{[19]}$ It was thought that platelets cannot produce new proteins as they are not nucleate cells. Such thought would definitely underestimate the synthesis capacities of platelets. The activated platelets are capable of producing proteins by a process called signal-dependent translation. ${ }^{[20]}$ Platelets produce interleukin- $1 b$ (IL-1b), which has the potential to either directly or indirectly to activate innate and acquired immune responses. ${ }^{[21,22]}$

Platelet-platelet and platelet-endothelial cell, and platelet-polymorphonuclear neutrophil play a crucial role in driving and modifying the early events in acute response to infection. ${ }^{[18]}$

Platelet interactions play a role in information transfer between effector cells of innate immune system to that of adaptive immune system, thus enabling transition to adaptive immune response. ${ }^{[23,24]}$ Platelets produce endogenous danger signals, i.e., CD40L and IL-1b that affect the dendritic cells activation in tissue injury. ${ }^{[25]}$ Platelets are found to produce lymphocyte trafficking and immunological memory in mice model. ${ }^{[26]}$ The breadth of interactions by activated platelets helps us in knowing the association between periodontitis and systemic diseases as well as the inflammatory status of the periodontium

MPV helps in measuring activated platelets. It can be defined as the size of the platelets on an average, calculated as a part of complete blood count. Its value ranges from 7.7 to $13.1 \mathrm{fL}$. Increased MPV value is seen in cases of diabetes mellitus, chronic renal failure, and pre-eclampsia. Decreased MPV value is seen in AIDS, hypersplenism, and cytotoxic chemotherapy.

MPV plays a critical role as a marker of inflammation in chronic inflammatory diseases, of which being periodontitis. ${ }^{[8]}$ High-grade inflammation is associated with decreased MPV, probably due to increased consumption of platelets at the site of inflammation. Once the inflammation is reduced, a reverse shift is seen ${ }^{[27]}$ Consumption of platelets in inflamed gingiva was inferred from histopathological observations revealing platelet aggregates and platelet adhesion to the endothelium or leukocytes in gingival biopsies. Platelets localized in inflamed gingivae were large platelets, as evidenced by their morphology on electron microscopy. ${ }^{[28]}$

Platelets adhering to the endothelium suggested the interaction between platelets and endothelial cells, which may be an initiating step in periodontal inflammation, resulting in the recruitment of leukocytes to periodontal tissue. The interaction between platelets and leukocytes is a means for the delivery of molecular signals and a critical step in the activation and recruitment of leukocytes to inflammatory sites for immunopathological responses. ${ }^{[29-31]}$ The circulation of leukocytes across the vascular endothelium is required for immune surveillance and for leukocyte recruitment at inflammatory sites. Platelet binding alters the adhesive and migratory phenotype of leukocytes, with platelet-monocyte and platelet-neutrophil complexes being more adhesive, thus resulting in enhanced transmigration through vascular endothelium. ${ }^{[32]}$

In addition, platelet aggregates and plateletleukocyte aggregates contribute to the synthesis 
and secretion of proinflammatory cytokines that have a known role in inflammation and tissue injury. ${ }^{[33]}$

The MPV value depends on the grade of inflammation, i.e., high or low and also on the antiinflammatory treatment the patient is upon. The possible reasons that can be attributed to the decrease in MPV at high inflammatory sites:

1. At sites with high inflammation, large number of platelets reach and get consumed, leading to a decrease in MPV value. At sites with lowgrade inflammation, platelets do not reach the inflammatory sites, but rather enter the circulation, and hence, the MPV value is decreased. ${ }^{[34]}$

2. At sites with high inflammation, due to the release of acute-phase proteins and proinflammatory cytokines, megakaryopoiesis is interfered, ultimately resulting in release of small-sized platelets from bone marrow. ${ }^{[35]}$

Positive correlation was observed between MPV and periodontitis and the MPV value increased to the value seen in healthy controls after active periodontal treatment (APT). ${ }^{[8]}$ This trend confirms that MPV and inflammatory status of periodontium are related.

Platelets were not only active in periodontitis patients but also hyperreactive. Platelets were thought to become less reactive after provision of non-surgical periodontal therapy. ${ }^{[36]}$

Positive correlation, however, existed in chronic generalized periodontitis patients and MPV, but MPV proved to be a less reliable indicator in case of generalized aggressive periodontitis subjects. ${ }^{[27]}$

MPV, which is an important marker in chronic inflammatory diseases, can help in diagnosing prethrombotic conditions. Thus, relating periodontitis and MPV could be a useful diagnostic parameter. ${ }^{[34,37]}$

The present study showed lower values of MPV before treatment compared to the values of MPV after APT. MPV value can be reliable marker for periodontitis. Increase in MPV values, thus, could be attributed to decrease inflammation as well as decrease risk to CVDs.

The limitations of our study include:

1. Smaller sample size.

2. Self-reported health of individuals.

3. Self-reported status of adverse habits such as smoking.

\section{CONCLUSION}

The present study concludes that the MPV values correlate with the severity of periodontal inflammation and can be used as a marker in diagnosing periodontal inflammatory status as well as a risk factor for CVDs. A successful periodontal intervention, thus, could manage the cardiovascular risk. Periodontal therapy could, thus, be projected to the medical community as a non-pharmacological intervention to improve the platelet activity.

\section{REFERENCES}

1. Trombelli L, Farina R, Silva CO, Tatakis DN. Plaque induced gingivitis: Case definition and diagnostic considerations. J Clin Periodontol 2018;45:44-67.

2. Loos BG. Systemic markers of inflammation in periodontitis. J Periodontol 2005;76:2106-15

3. Paraskevas S, Huizinga JD, Loos BG. A systematic review and meta-analyses on C-reactive protein in relation to periodontitis. J Clin Periodontol 2008;35:277-90.

4. Danesh J, Collins R, Appleby P, Peto R. Association of fibrinogen, C-reactive protein, albumin, or leukocyte count with coronary heart disease: Meta-analyses of prospective studies. JAMA 1998;279:1477-82.

5. Loos BG, Craandijk J, Hoek FJ, Wertheim-van Dillen PM, van der Velden U. Elevation of systemic markers related to cardiovascular diseases in the peripheral blood of periodontitis patients. J Periodontol 2000;71:1528-34.

6. Loimaala A, Rontu R, Vuori I, Mercuri M, Lehtimäki T, Nenonen A, et al. Blood leukocyte count is a risk factor for intima-media thickening and subclinical carotid atherosclerosis in middle-aged men. Atherosclerosis 2006 188:363-9.

7. Papapanagiotou D, Nicu EA, Bizzarro S, Gerdes VE, Meijers JC, Nieuwland R, et al. Periodontitis is associated with platelet activation. Atherosclerosis 2009;202:605-11.

8. Wang X, Meng H, Xu L, Chen Z, Shi D, Lv D, et al. Mean platelet volume as an inflammatory marker in patients with severe periodontitis. Platelets 2015;26:67-71.

9. Herd CM, Page CP. Do platelets have a role as inflammatory cells? In: Joseph M, editor. Immunopharmacology of Platelets. London, San Diego, New York, Boston, Sydney, Tokyo, Totonto: Academic Press; 1995. p. 1-20.

10. Klinger $\mathrm{MH}$. Inflammation. In: Michelson $\mathrm{AD}$, editor Platelets. $2^{\text {nd }}$ ed. San Diego: Elsevier Academic Press; 2000. p. 459-67.

11. Yeaman MR, Bayer AS. Antimicrobial host defense. In Michelson AD, editor. Platelets. London: Academic Press; 2002. p. 469-82.

12. Brandt E, Ludwig A, Petersen F, Flad HD. Platelet-derived CXC chemokines: Old players in new games. Immunol Rev 2000;177:204-16.

13. Boehlen F, Clemetson KJ. Platelet chemokines and their receptors: What is their relevance to platelet storage and 
transfusion practice? Transfus Med 2001;11:403-17.

14. Romagnani P, Lasagni L, Annunziato F, Serio M, Romagnani S. CXC chemokines: The regulatory link between inflammation and angiogenesis. Trends Immunol 2004;25:201-9.

15. Krijgsveld J, Zaat SA, Meeldijk J, van Veelen PA, Fang G, Poolman B, et al. Thrombocidins, microbicidal proteins from human blood platelets, are C-terminal deletion products of CXC chemokines. J Biol Chem 2000;275:20374-81.

16. Weyrich AS, Zimmerman GA. Platelets: Signaling cells in the immune continuum. Trends Immunol 2004:25:489-95.

17. McIntyre TM, Prescott SM, Weyrich AS, Zimmerman GA Cell-cell interactions: Leukocyte-endothelial interactions. Curr Opin Hematol 2003;10:150-8.

18. Nathan C. Points of control in inflammation. Nature 2002; 420:846-52

19. Patrono C, Patrignani P, Rodríguez LA. Cyclooxygenaseselective inhibition of prostanoid formation: Transducing biochemical selectivity into clinical read-outs. J Clin Invest 2001;108:7-13.

20. Weyrich AS, Lindemann S, Zimmerman GA. The evolving role of platelets in inflammation. J Thromb Haemost 2003; 1:1897-905.

21. Kaplanski G, Marin V, Montero-Julian F, Mantovani A, FarnarierC.IL-6:Aregulator of the transition fromneutrophil to monocyte recruitment during inflammation. Trends Immunol 2003;24:25-9.

22. Loppnow H, Bil R, Hirt S, Schonbeck U, Herzberg M, Werdan $\mathrm{K}$, et al. Platelet-derived interleukin-1 induces cytokine production, but not proliferation of human vascular smooth muscle cells. Blood 1998;91:134-41.

23. Chertov O, Yang D, Howard OM, Oppenheim JJ. Leukocyte granule proteins mobilize innate host defenses and adaptive immune responses. Immunol Rev 2000;177:68-78.

24. Medzhitov R, Janeway C Jr. Innate immunity. N Engl J Med 2000;343:338-44

25. Gallucci S, Matzinger P. Danger signals: SOS to the immune system. Curr Opin Immunol 2001;13:114-9.

26. Diacovo TG, Catalina MD, Siegelman MH, von Andrian UH. Circulating activated platelets reconstitute lymphocyte homing and immunity in L-selectin-deficient mice. J Exp Med 1998;187:197-204

27. Gasparyan AY, Sandoo A, Stavropoulos-Kalinoglou A, Kitas GD. Mean platelet volume in patients with rheumatoid arthritis: The effect of anti-TNF-alpha therapy. Rheumatol Int 2010;30:1125-9.

28. Zhan Y, Lu R, Meng H, Wang X, Hou J. Platelet activation and platelet-leukocyte interaction in generalized aggressive periodontitis. J Leukoc Biol 2016;100:1155-66.

29. Pitchford SC, Riffo-Vasquez Y, Sousa A, Momi S, Gresele P, Spina D, et al. Platelets are necessary for airway wall remodeling in a murine model of chronic allergic inflammation. Blood 2004;103:639-47.

30. Pitchford SC, Momi S, Giannini S, Casali L, Spina D, Page CP, et al. Platelet P-selectin is required for pulmonary eosinophil and lymphocyte recruitment in a murine model of allergic inflammation. Blood 2005;105:2074-81.

31. Zarbock A, Singbartl K, Ley K. Complete reversal of acidinduced acute lung injury by blocking of platelet-neutrophil aggregation. J Clin Invest 2006;116:3211-9.

32. Page C, Pitchford S. Neutrophil and platelet complexes and their relevance to neutrophil recruitment and activation. Int Immunopharmacol 2013;17:1176-84.

33. Vito CD, Hadi LA, Navone SE, Marfia G, Campanella R, Mancuso ME, etal.Platelet-derived sphingosine-1-phosphate and inflammation: From basic mechanisms to clinical implications. Platelets 2016;27:393-401.

34. Gasparyan AY, Ayvazyan L, Mikhailidis DP, Kitas GD. Mean platelet volume: A link between thrombosis and inflammation? Curr Pharm Des 2011;17:47-58.

35. Bath PM, Butterworth RJ. Platelet size: Measurement, physiology and vascular disease. Blood Coagul Fibrinolysis 1996;7:157-61.

36. Arvanitidis E, Bizzarro S, Rodriguez EA, Loos BG, Nicu EA. Reduced platelet hyper-reactivity and platelet-leukocyte aggregation after periodontal therapy. Thrombosis J 2017; 15:5.

37. Chu SG, Becker RC, Berger PB, Bhatt DL, Eikelboom JW, Konkle B, et al. Mean platelet volume as a predictor of cardiovascular risk: A systematic review and meta-analysis. J Thromb Haemost 2010;8:148-56. 